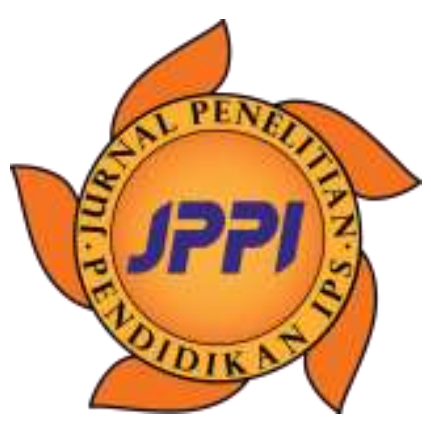

Info Artikel

Keyword:

Prolem Based Learning Model, Learning Motivation, Learning Outcomes.

Korespondensi Penulis: Lilik Rachmawati:

E-mail:

krnwn46@gmail.com

ISSN (print): 1858-4985

ISSN (on-line): 2721-8821

\section{Pengaruh Model Pembelajaran Berbasis Masa- lah Terhadap Motivasi Belajar Dan Hasil Belajar Pada Mata Pelajaran Geografi Di SMA Tahfidz Darul Ulum Banyuanyar Pamekasan}

\author{
Andri Kurniawa ${ }^{1,2}$ \\ ${ }^{1}$ SMA Tahfidz Darul Ulum Banyuanyar Pamekasan, \\ Malang, 65216, Indonesia \\ ${ }^{2}$ Program Pascasarjana Universitas Kanjuruhan Malang \\ Jl. S. Supriyadi No. 48 Malang, 65148, Indonesia
}




\section{PENDAHULUAN}

Masalah utama dalam pembelajaran pendidikan formal (sekolah) dewasa ini adalah masih rendahnya daya serap peserta didik. Hal ini tampak dari rata-rata hasil belajar peserta didik yang senantiasa masih sangat memprihatinkan. Prestasi ini tentunya merupakan hasil kondisi pembelajaran yang tidak menyentuh dan menarik minat dan motivasi bagi peserta didik itu sendiri dan sebab dominannya proses pembelajaran yang masih teacher centre atau bisa dikatakan masih berpusat pada guru, guru yang hanya memberikan materi-materi tanpa adanya hubungan timbal balik bagi siswa yang cenderung membuat peserta didik malas mengikuti pelajaran [1].

Selain itu, rendahnya pencapaian kompetensi peserta didik juga disebabkan oleh proses pembelajaran yang lebih berpusat pada pendidik, peserta didik kurang mampu membangun konsep mereka sendiri, peserta didik masih kurang diberi ruang untuk mengungkapkan kreasi berpikirnya sehingga peserta didik pasif dalam pembelajaran [2].

Peran guru atau pendidik dalam proses pembelajaran pada umumnya hanya memindahkan informasi pengetahuan dari buku atau dari guru ke peserta didik, sedangkan tugas peserta didik hanya menerima, menghafal, maupun mengingat materi yang diajarkan tersebut. Hal seperti inilah yang menyebabkan siswa menjadi terkesan pasif dan kurang mengambil peran sehingga nilai akhir yang diraih pun menjadi kurang memuaskan [3].

Pembelajaran yang baik adalah pembelajaran yang berpusat pada siswa (student centered) sehingga siswa akan memiliki pengalaman langsung dalam belajar. Guru atau tenaga pengajar kini tidak lagi merupakan satu-satunya nara sumber dalam proses pembelajaran. Teknologi komunikasi dan informasi yang kini ada dan juga akan terus berkembang, semakin memungkinkan peserta didik untuk mengakses sendiri beragam sumber belajar [4]. Karena itu, jika guru tetap ingin memainkan peran sentral dalam proses pembelajaran, mereka harus melakukan perubahan-perubahan atau setidaknya penyesuaian dalam paradigma, strategi, pendekatan, dan teknologi pembelajaran. Jika tidak, guru atau tenaga pengajar akan kehilangan makna kehadiran dalam proses pembelajaran [5].

Keberhasilan dalam pembelajaran dapat dilihat dari pencapaian hasil belajar siswa. hasil belajar bukan hanya berupa penguasaan pengetahuan, tetapi juga kecakapan dan keterampilan dalam melihat, menganalisis, dan memecahkan masalah, membuat rencana dan mengadakan pembagian kerja sehingga baik kegiatan maupun produk yang dihasilkan dari ativitas belajar ini mendapatkan penilaian [6].

Hasil belajar adalah bagian yang sangat penting dan tidak terpisahkan dalam proses pembelajaran. Hasil belajar diketahui setelah adanya evaluasi atau penilaian hasil belajar. Hasil belajar digunakan untuk mengetahui sejauh mana siswa berhasil mencapai tujuan pembelajaran dan memperoleh perubahan perilaku setelah proses pembelajaran sehingga dapat diperoleh gambaran tentang pencapaian program pendidikan. Hasil belajar juga penting bagi guru sebagai umpan balik untuk mengetahui kelebihan dan kekurangan gurudalam mengajar sehingga dapat memperbaiki proses pembelajaran selanjutnya [7].

Sejalan dengan dinamika pendidikan yang ada, terutama dalam kegiatan pembelajaran, dan khususnya dalam kegiatan pembelajaran di kelas dimana guru sebagai pengelola kelas tersebut, akan sangat diharapakan adanya keefektifan dan idealisasi untuk mencapai tujuan pembelajaran yang sudah direncanakan. Idealisasi dan efektifitas pembelajaran itu tidak akan sama pada masing-masing kegiatan, karena tentunya dipengaruhi oleh perbedaan level pendidikan, tingkat kesulitan pelajaran, kualitas siswa itu sendiri, sarana, waktu, metode, dan lain sebagainya. Guru sebagai pengelola pembelajaran diharapkan supaya mampu membaca faktor-faktor itu semua sehingga tujuan pembelajaran yang diharap dan direncanakan dapat tercapai dengan maksimal [8].

Agar proses belajar dapat berjalan sesuai dengan yang guru inginkan, maka siswa memerlukan motivasi. Motivasi adalah kekuatan, baik dari dalam maupun luar yang mendorong seseorang untuk mencapai tujuan tertentu yang ditetapkan sebelumnya [9].

Motivasi dipengaruhi oleh beberapa faktor baik itu faktor internal maupun faktor eksternal. Faktor internal merupakan faktor yang timbul dari dalam diri siswa, seperti kondisi kesehatan, minat belajar, dan lain sebagainya. Sedangkan faktor eksternal merupakan faktor yang berpengaruh yang timbul dari luar siswa, seperti Guru, lingkungan (keluarga, sekolah, masyarakat), ketersediaan sarana dan prasarana, metode dan strategi mengajar [10].

Motivasi merupakan daya penggerak yang menjamin terjadinya kelangsungan kegiatan belajar dan memberikan arah pada kegiatan belajar sehingga tujuan yang diinginkan dapat terpenuhi. Dengan 
demikian motivasi sangat berpengaruh terhadap hasil belajar seseorang. Apabila seseorang tidak mempunyai motivasi untuk belajar, maka orang tersebut tidak akan mencapai hasil belajar yang optimal. Motivasi belajar yang ada dalam diri siswa yang satu dengan yang lain berbeda-beda, ada siswa yang motivasi belajarnya tinggi dan ada juga yang motivasi belajarnya rendah [11].

Permasalahan dan fenomena tersebut tentulah harus dicarikan solusi dan upaya untuk memperbaikinya. Salah satu upaya yang dapat dilakukan adalah dengan menciptakan suasana belajar yang melibatkan siswa dalam proses pembelajaran. Dengan menerapkan model pembelajaran yang lebih inovatif diharapkan dapat meningkatkan hasil belajar maupun motivasi siswa. Menurut Arends dalam Trianto (2009), salah satu model pembelajaran yang dapat mengaktifkan siswa adalah model PBL. Pembelajaran dengan model PBL didasarkan pada prinsip bahwa masalah dapat digunakan sebagai titik awal untuk mendapatkan pengetahuan. Masalah yang disajikan dalam pembelajaran diharapkan dapat meningkatkan motivasi siswa dalam memahami konsep dan teori pembalajaran [12].

Selain itu, rasa semangat dan pemahaman siswa terhadap materi pembelajaran harus tetap dijaga dengan selalu mengaktifkan siswa di dalam kelas pada saat proses KBM berlangsung. Salah satu model pembelajaran yang dapat mengaktifkan serta memenuhi kebutuhan belajar peserta didik yang beragam yaitu model PBL (Problem Based Learning) [13]. Menurut Duch (dalam Rianto, 2009), menyatakan bahwa pembelajaran berbasis masalah adalah suatu model pembelajaran yang menghadapkan peserta didik pada tantangan "belajar untuk belajar". Siswa aktif bekerja sama di dalam kelompok untuk mencari solusi permasalah dunia nyata. Model ini dimaksudkan oleh Duch untuk mengembangkan kemampuan siswa berpikir kritis, analitis, menemukan serta menggunakan sumber daya yang sesuai untuk belajar [14].

\section{METODE}

Rancangan dalam penelitian ini menggunakan True Eksperimen Design atau rancangan eksperimen sungguhan tipe Pretest- Postest Control Group Desaign atau the Randomized Pretest-Postest Control Group Design,

Penelitian ini dilakukan di kelas XI IPS 1 \& 2 di SMA Darul Ulum Banyuanyar yang terletak di Desa Potoan Daya Kecamatan Palengaan Kabupaten Pamekasan, penelitian ini yang menjadi populasi adalah siswa kelas XI IPS I yang memiliki 55 siswa dan kelas XI IPS II yang memiliki 55 siswa di SMA Tahfidz Darul Ulum Banyuanyar tahun ajaran 2019/2020,

Sedangkan tekhnik pengambilan sampel dalam sebuah penelitian menggunakan tekhnik Probability Sampling dan NonProbability Sampling, Dalam penelitian ini sampelnya adalah sebagian siswa kelas XI IPS 1 yang dijadikan sampel untuk kelompok Eksperimen \& sebagian siswa kelas XI IPS 2 yang dijadikan sampel untuk kelompok Kontrol. Sedangkan Teknik pengambilan sampelnya untuk kelompok eksperimen dan kelompok kontrol menggunakan teknik ${ }^{\text {Simple }}$ Random Sampling sampling atau pengambilan sampelnya secara random atau acak, Setelah teknik pengambilan sampel di tentukan maka selanjutnya menentukan ukuran sampel. Ukuran sampel (sample size) adalah banyaknya individu, subyek atau elemen dari populasi yang diambil sebagai sampel.

Sampel yang baik adalah sampel yang memberikan pencerminan optimal terhadap populasinya (representative). Menurut Gay \& Diehl (1992 : 146) dalam Amirullah berpendapat bahwa sampel haruslah sebesar-besarnya. Pendapat ini mengasumsikan bahwa semakin banyak sampel yang diambil, maka akan semakin representatif, dan hasilnya dapat di generalisir. Namun, ukuran sampel yang dapat diterima akan sangat bergantung pada jenis penelitiannya, apabila penelitian eksperimental, sampel minimunnya adalah 15 subyek per group. Sedangkan menurut Roscoe (1975) memberikan panduan untuk menentukan ukuran sampel Pada setiap penelitian, ukuran sampel harus berkisar antara 30 dan 500 . Menurut Gay, Mills dan Airasian (2009: 133) dalam Idrus Alwi mengatakan untuk penelitian eksperimen dan komparatif diperlukan sampel 30 responden untuk setiap kelompok yang akan dibandingkan. Khusus untuk penelitian eksperimen dan komparatif, menurut Borg and Gall (2007: 176) diperlukan sampel 15-30 responden setiap kelompok. Sedangkan Slovin (1960), dalam Sevila (2007) dalam Amirullah mengatakan dalam menentukan ukuran sampel dari suatu populasi dengan rumus sebagai berikut: 


$$
\mathrm{n}=\frac{\mathrm{N}}{1+\mathrm{N}(\mathrm{e})^{2}}
$$

Di mana $: \mathrm{n}=$ jumlah sampel

$$
\begin{aligned}
& \mathrm{N}=\text { ukuran populasi } \\
& \mathrm{e}=\text { batas kesalahan }
\end{aligned}
$$

Dalam penelitian ini untuk menentukan besarnya sampel atau jumlah sampel dalam penelitian ini menggunakan rumus dari Taro Yamane yang hamper sama dengan rumusnya Slovin sebagai berkut:

Teknik Taro Yamane.

$$
\mathrm{n}=\frac{\mathrm{N}}{1+\mathrm{N}(\mathrm{d})^{2}}
$$

Keterangan

$$
\begin{aligned}
& \mathrm{n}=\text { Jumlah sampel } \\
& \mathrm{N}=\text { Jumlah populasi } \\
& \mathrm{d}^{2}=\text { Nilai presisi }(5 \% \text { atau } 0,05)
\end{aligned}
$$

Penghitungannya sebagai berikut :

\section{5}

$$
\mathrm{n}=\frac{}{1+55(0,05)^{2}}=48,35 \text { di bulatkan menjadi } 49 .
$$

Jadi besarnya sampel yang akan diteliti dalam penelitian ini sebanyak 49 responden, dengan rincian jumlah sampel pada masing-masing kelas.

Pelaksanaan penelitian ini melalui beberapa tahapan, yaitu:

1. Tahap Persiapan.

Tahap persiapan merupakan tahap awal yang dipersiapkan dalam penelitian. Tahap persiapan ini meliputi:

a. Membuat dan menyiapkan instrument penelitian.

b. Melakukan uji coba instrument, untuk mengetahui validitas dan reliabilitas instrument penelitian.

c. Menyiapakn RPP, materi pembelajaran, media pembelajaran dan melaksanakan proses pemebelajaran dengan model PBM.

\section{Tahap Pelaksanaan.}

a. Tahap Pretest

Pretest yaitu tes awal atau uji kemampuan awal kepada kelompok eksperimen dan kelompok kontrol sebelum mendapatkan perlakuan dengan model pembelajaran berbasis masalah. Pretest ini diberikan dengan tujuan untuk mnegetahui kemampuan awal kelompok eksperimen 
maupun kelompok kontrol, sehingga diketahui sejauh mana motivasi belajar dan hasil belajar siswa dari kedua kelompok tersebut sebelum diberi perlakuan / treatment dengan model pembelajaran berbasis masalah.

b. Tahap Pembelajaran

Tahap pembelajaran adalah tahapan yang menjadi acuan dalam penelitian ini. Tahapan pembelajaran untuk kelompok eksperimen dan kelompok kontrol telah dibedakan. Kelompok eksperimen dalam kegiatan belajar mengajarnya menggunakan treatment berupa penggunaan Model Pembelajaran Berbasis Masalah (PBM) dan Media Pembelajaran. Sedangkan untuk kelompok control dalam kegiatan belajarnya tidak menggunakan model pembelajaran berbasis masalah tetapi menggunakan model yang konvensional yaitu dengan metode ceramah dan tanya jawab dan menggunakan media papan tulis dalam proses penyampaian materinya.

c. Tahap Posttest

Tahap terakhir dalam proses pembelajaran ini yaitu pemberian posttest. Posttest diberikan untuk mengetahui motivasi belajar dan hasil belajar dari kelompok eksperimen yang diberi perlakuan pembelajaran dengan Model Pembelaharan Berbasis Masalah sedangkan kelompok kontrol yang tidak menggunakan model Pembelajaran Berbasis Maslah.

3. Tahap Evaluasi dan Pembuatan Laporan

Tahap evaluasi yaitu tahapan penelitian mengenai pengolahan data terhadap motivasi belajar dan hasil belajar siswa. Dalam tahap evaluasi ini dibandingkan antara kelompok eksperimen dengan kelompok kontrol untuk penyusunan laporan penelitian tersebut.

Dalam analisis menggunakan Statistik Parametrik, distribusi data menyebar secara normal adalah mutlak, Penggunaan Statistik Parametris mensyaratkan bahwa data setiap variabel yang akan dianalisa harus berdistribusi normal. Uji normalitas adalah cara untuk menetapkan apakah distribusi data dalam sampel dapat secara masuk akal dianggap berasal dari populasi tertentu yang berdistribusi normal.

Dalam penelitian ini teknik yang digunakan untuk melakukan pengujian normalitas data menggunakan tekhnik Kolmogorov Smirnov dengan proses penghitungannya menggunakan SPSS for Windows versi 21.

Pengujian hipotesis dalam penelitian ini menggunakan uji independent sampel t-test dengan bantuan SPSS for windows versi 21. Uji independent sampel t-test digunakan untuk mengetahui perbedaan rata-rata dua populasi atau kelompok data yang independent. Uji uji independent sampel t-test memiliki syarat yang harus dipenuhi yaitu, data berdistribusi normal dan keuda kelompok data independent. Sedangkan kaidah keputusannya adalah

1. Jika nilai signifikansi t (sig 2-tailed) lebih kecil dari 0,05 (P < 0,05) maka nilai t hitung signifikan atau ada perbedaan rata-rata dari dua kelompok data.

2. Jika nilai signifikansi t (sig 2-tailed) lebih besar dari 0,05 (P > 0,05) maka nilai t hitung tidak signifikan atau tidak ada perbedaan rata-rata dari dua kelompok data

\section{HASIL DAN PEMBAHASAN}

\section{Deskripsi Data}

Uji validitas instrument dilakukan di MA Darul Ulum Banyuanyar Pamekasan pada kelas XI dan kelas $\mathrm{X}$ dengan jumlah responden 49 orang untuk masing-masing angket / kuisioner. Uji validitas instrument dilakukan di MA Darul Ulum Banyuanyar Pamekasan karena peneliti juga mengajar pada lembaga tersebut pada maple Geografi serta kondisi MA Darul Ulum Banyuanyar Pamekasan tidak jauh berbeda / hampir sama dengan lembaga yang menjadi tempat penelitian yaitu di SMA Tahfidz Darul Ulum Banyuanyar.

Hasil analisis uji validitas instrument non test yang berupa angket atau kuisioner disajikan dalam tabel berkut: 
Tabel 1 Hasil Uji Validitas Instrumen Angket Motivasi Intrinsik

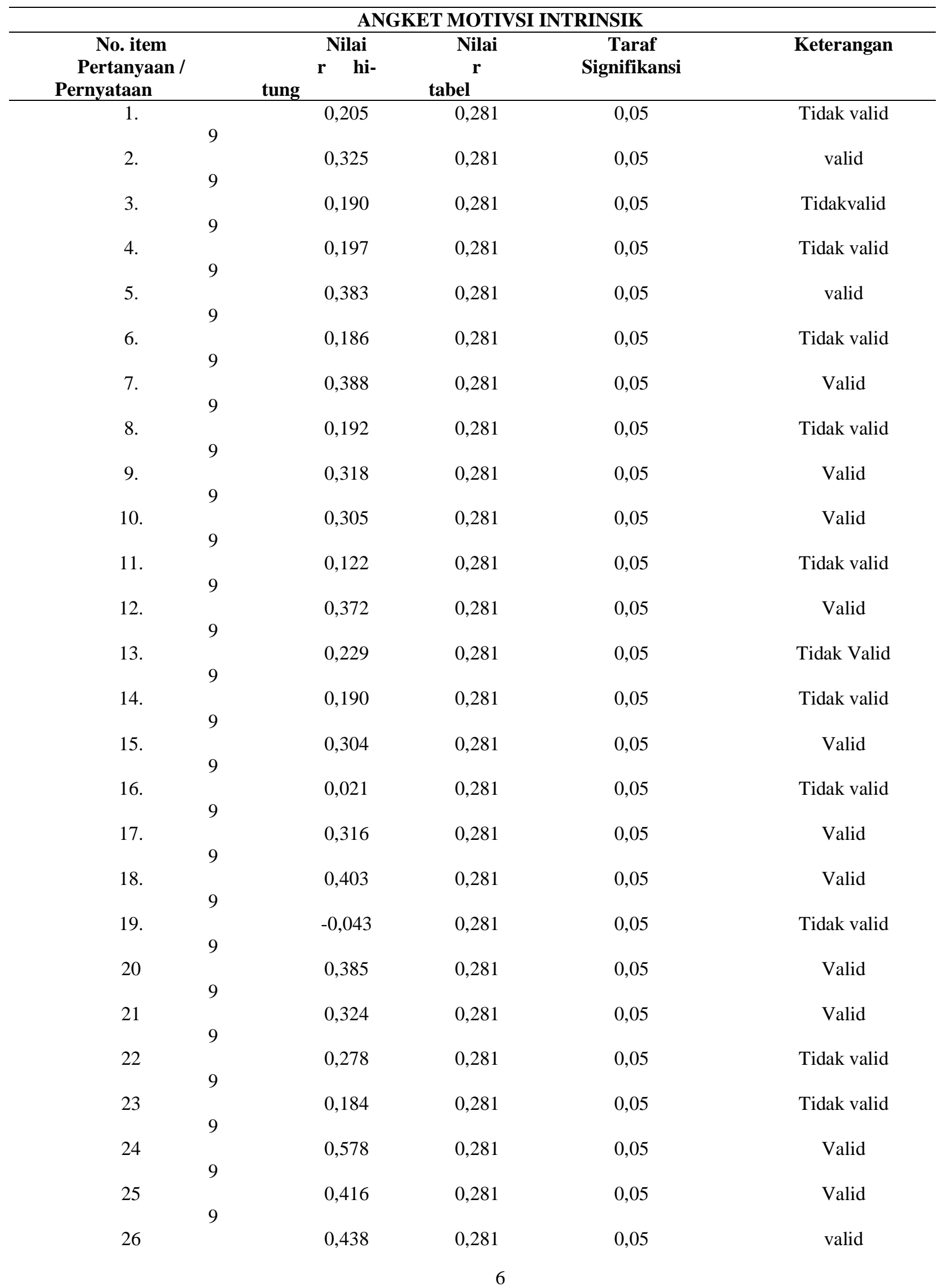


Tabel 2 Hasil Uji Validitas Instrumen Angket Motivasi Ekstrinsik.

\begin{tabular}{|c|c|c|c|c|c|}
\hline \multicolumn{6}{|c|}{ Angket Motivasi Ekstrinsik. } \\
\hline $\begin{array}{c}\text { No. item } \\
\text { Pertanyaan / } \\
\text { Pernyataan }\end{array}$ & & $\begin{array}{c}\text { Nilai } \\
\text { r hitung }\end{array}$ & $\begin{array}{l}\text { Nilai } \\
\text { r table }\end{array}$ & $\begin{array}{c}\text { Taraf } \\
\text { Signifikansi }\end{array}$ & Keterangan \\
\hline 1 & & $-0,023$ & 0,281 & 0,05 & Tidak valid \\
\hline 2. & 9 & 0,572 & 0,281 & 0,05 & Valid \\
\hline 3. & 9 & $-0,089$ & 0,281 & 0,05 & Tidak valid \\
\hline 4. & 9 & 0,194 & 0,281 & 0,05 & Tidak valid \\
\hline 5. & 9 & 0,241 & 0,281 & 0,05 & Tidak valid \\
\hline 6. & 9 & 0,052 & 0,281 & 0,05 & Tidak valid \\
\hline 7. & 9 & 0,039 & 0,281 & 0,05 & Tidak valid \\
\hline 8. & 9 & 0,282 & 0,281 & 0,05 & Valid \\
\hline 9. & 9 & 0,286 & 0,281 & 0,05 & Valid \\
\hline 10. & 9 & 0,350 & 0,281 & 0,05 & Valid \\
\hline 11. & 9 & 0,263 & 0,281 & 0,05 & Tidak valid \\
\hline 12. & 9 & 0,293 & 0,281 & 0,05 & Valid \\
\hline 13. & 9 & 0,091 & 0,281 & 0,05 & Tidak valid \\
\hline 14. & 9 & 0,324 & 0,281 & 0,05 & Valid \\
\hline 15. & 9 & 0,224 & 0,281 & 0,05 & Tidak valid \\
\hline 16. & 9 & 0,253 & 0,281 & 0,05 & Tidak valid \\
\hline 17. & 9 & 0,211 & 0,281 & 0,05 & Tidak valid \\
\hline 18. & 9 & 0,267 & 0,281 & 0,05 & Tidak valid \\
\hline 19. & 9 & 0,332 & 0,281 & 0,05 & Valid \\
\hline 20. & 9 & 0,050 & 0,281 & 0,05 & Tidak valid \\
\hline 21. & 9 & 0,308 & 0,281 & 0,05 & Valid \\
\hline 22. & 9 & 0,148 & 0,281 & 0,05 & Tidak valid \\
\hline 23. & 9 & 0,309 & 0,281 & 0,05 & Valid \\
\hline 24. & 9 & 0,463 & 0,281 & 0,05 & Valid \\
\hline 25. & & 0,238 & 0,281 & 0,05 & Tidak valid \\
\hline
\end{tabular}




\begin{tabular}{|c|c|c|c|c|}
\hline $\begin{array}{l}9 \\
9\end{array}$ & 0,232 & 0,281 & 0,05 & Tidak valid \\
\hline \multicolumn{5}{|c|}{$\begin{array}{l}\text { Tabel.3 Nomor dan Jumlah item pertanyaan / pernyataan pada angket } \\
\text { yang valid dan yang tidak valid. }\end{array}$} \\
\hline Instrumen & $\begin{array}{c}\text { Nomor } \\
\text { item yang valid }\end{array}$ & $\begin{array}{l}\text { Nomor } \\
\text { item yang tidak } \\
\text { valid }\end{array}$ & $\begin{array}{c}\text { Jumlah } \\
\text { Item yang valid }\end{array}$ & $\begin{array}{l}\text { Jumlah } \\
\text { Item yang tid- } \\
\text { ak valid }\end{array}$ \\
\hline $\begin{array}{l}\text { Angket Motivasi Bela- } \\
\text { jar Instrinsik }\end{array}$ & $\begin{array}{l}2,5,7,9,10 \\
12,15,17,1 \\
8 \\
20,21,24,2 \\
5 \\
26\end{array}$ & $\begin{array}{c}1,3,4,6,8,11 \\
13,14,16,19 \\
22,23\end{array}$ & 14 & 12 \\
\hline $\begin{array}{l}\text { Angket Motivasi Bela- } \\
\text { jar Ekstrinsik }\end{array}$ & $\begin{array}{l}2,8,9,10,1 \\
2 \\
14,16,19,2 \\
2 \\
23\end{array}$ & $\begin{array}{c}1,3,4,5,6,7 \\
11,13,15,16 \\
17,18,20,22 \\
25,26\end{array}$ & 10 & 16 \\
\hline
\end{tabular}

Item / butir pertanyaan /pernyataan yang valid pada angket motivasi belajar intrinsik dan ekstrinsik tersebut di dasarkan pada nilai $r$ hitung yang lebih besar dari nilai $r$ tabel $(0,281)$ dengan jumlah sampel (n) 49 dan taraf signifikansi sebesar 0,05

Tabel. 4 Hasil Uji Reliablitas Instrumen Angket Motivasi Intrinsik dan Ekstrinsik

\begin{tabular}{|c|c|c|c|c|c|c|c|c|}
\hline Instrumen & & Mean & $\begin{array}{l}\text { Std. } \\
\text { tion }\end{array}$ & Devia- & $\begin{array}{l}\text { Nilai } \\
\text { Cronbach }\end{array}$ & Alpha & Taraf Signifikansi & Keterangan \\
\hline $\begin{array}{l}\text { Angket Motiva- } \\
\text { si Belajar In- } \\
\text { trinsik }\end{array}$ & 9 & $10^{48 .}$ & & 3.959 & & 0,627 & 0,6 & RELIABEL \\
\hline $\begin{array}{l}\text { Angket Motiva- } \\
\text { si Belajar } \\
\text { Ekstrinsik }\end{array}$ & 9 & $35^{34 .}$ & & 2.728 & & 0,453 & 0,6 & $\begin{array}{l}\text { TIDAK } \\
\text { LIABEL }\end{array}$ \\
\hline
\end{tabular}

Berdasarkan tabel 4.4 diatas, diketahui pada angket motivasi belajar intrinsik nilai Meannya 48,10, nilai Standard Deviasinya 3.959 dan nilai Alpha Cronbach sebesar 0,627 yang lebih besar dari 0,60 yang artinya Reliabel atau ada 14 item / butir pertanyaan / pernyataan yang dapat digunakan untuk mengukur motivasi belajar intrinsik.

Sedangkan pada angket motivasi ekstrinsik, diketahui nilai Meannya 34.35, nilai Standard Deviasinya 2.728 sedangkan nilai nilai Alpha Cronbach sebesar 0,453 yang lebih kecil dari 0,60 yang artinya tidak reliabel atau 10 item / butir pertanyaan / pernyataan tersebut tidak dapat digunakan untuk mengukur motivasi belajar ekstrinsik.

Tabel 5 Hasil Uji Kemampuan Awal Data Pre-test

Hasil Belajar Kelompok Eksperimen dan Kelompok Kontrol

\begin{tabular}{lccccl} 
Kelas & $\alpha$ & $\begin{array}{c}\text { M } \\
\text { ean }\end{array}$ & $\begin{array}{c}\text { Std } \\
\text { Devi- } \\
\text { ation }\end{array}$ & $\begin{array}{l}\text { 1 Sig } \\
\text { (2-tailed) })\end{array}$ & $\begin{array}{l}\text { Jika P }>0,05 \text { atau } \\
\text { Sig(2-tailed) }>0,05 \\
\text { ada perbedaan }\end{array}$ \\
\hline Eksperimen & 3,39 & 7 & 1.730 & & \\
\hline
\end{tabular}




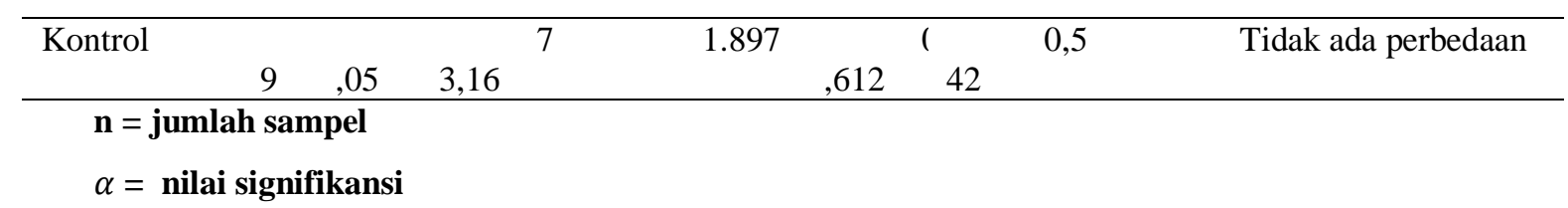

Berdasarkan tabel 5 diatas, diketahui bahwa kelas eksperimen memiliki nilai mean 73,39 dan nilai standard deviasi 1,730, sedangkan nilai mean pada kelas Kontrol sebesar 73,16 dan nilai standard deviasi 1,897. Sedangkan nilai $t$ dan nilai signifikansi t (sig 2- tailed) pada kelas eksperimen dan kelas kontrol sebesar 0,612 dan 0,542.

Dan berdasarkan nilai signifikasnsi t (sig 2- tailed) pada kelas eksperimen dan kelas kontrol sebesar 0,542 yang lebih besar dari 0,05 yang artinya tidak ada perbedaan hasil belajar antara Kelas Eksperimen dan Kelas Kontrol sebelum mendapatkan perlakuan dengan Model Pembelajaran Berbasis Masalah.

Tabel. 6 Hasil Uji Kemampuan Awal Data Pre-test

Motivasi Belajar Kelompok Eksperimen dan Kelompok Kontrol

\begin{tabular}{|c|c|c|c|c|c|c|c|c|}
\hline Kelas & & $\alpha$ & Mean & $\begin{array}{l}\text { Std } \\
\text { Deviation }\end{array}$ & $\mathbf{T}$ & & $\begin{array}{l}\text { Sig } \\
\text { (2-tailed) }\end{array}$ & $\begin{array}{l}\text { Jika } P>0,05 \text { atau Sig(2- } \\
\text { tailed) }>0,05=\text { tidak ada } \\
\text { perbedaan }\end{array}$ \\
\hline Eksperimen & & & & 3,142 & & & & \\
\hline Kontrol & 9 & ,05 & $\begin{array}{l}8,14 \\
8,12\end{array}$ & 2,306 & ,037 & 0 & 0,97 & Tidak ada perbedaan \\
\hline
\end{tabular}

Berdasarkan tabel 6 diatas, diketahui bahwa hasil uji kemampuan awal motivasi belajar kelas eksperimen nilai mean-nya 48,14 dan nilai standard deviasi-nya 3,142, sedangkan nilai mean pada kelas Kontrol sebesar 48,14, dan nilai standard deviasi-nya 48,12. Sedangkan nilai $t$ dan nilai signifikansi $t$ (sig 2- tailed) pada kelas eksperimen dan kelas kontrol sebesar 0,037 dan 0,971.

Dan berdasarkan nilai signifikasnsi t (sig 2- tailed) pada kelas eksperimen dan kelas kontrol sebesar 0,971 yang lebih besar dari 0,05 yang artinya tidak ada perbedaan motivasi belajar antara Kelas Eksperimen dan Kelas Kontrol sebelum mendapatkan perlakuan dengan Model Pembelajaran Berbasis Masalah.

Tabel 7 Hasil Uji Normalitas Data Pos-test Hasil Belajar Kelompok Eksperimen dan Kontrol.

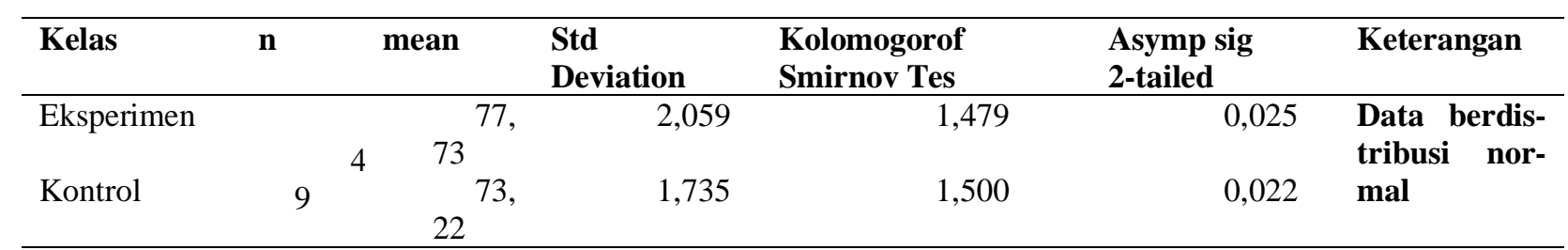

Untuk lebih jelasnya lihat lampiran 15.

Berdasarkan tabel 7 di atas, diketahui nilai Asymp Sig 2-tailed untuk kelompok Eksperimen sebesar 0,025. Sedangkan nilai Asymp Sig 2-tailed untuk kelompok Kontrol sebesar 0,022, dimana nilai Asymp Sig 2-tailed antara kelompok eksperimen dan kelompok kontrol lebih besar dari 0,05 yang 
artinya data post test hasil belajar kelompok eksperimen dan kelompok kontrol berdistribusi normal.

Tabel 8 Hasil Uji Normalitas Data Post-test Motivasi Belajar Kelompok Eksperimen dan Kontrol.

\begin{tabular}{|c|c|c|c|c|c|c|c|}
\hline Kelompok & $\begin{array}{l}\text { Motivasi } \\
\text { Belajar }\end{array}$ & & $\begin{array}{l}\text { Hasil } \\
\text { Kolomogorof } \\
\text { Smirnov Test }\end{array}$ & Asymp Sig & $\begin{array}{l}\text { Taraf } \\
\text { ikansi }\end{array}$ & Signif- & Keterangan \\
\hline Eksperimen & Intrinsik & & 1,542 & $7^{0,01}$ & & 0,05 & $\begin{array}{l}\text { Data berdistri- } \\
\text { busi normal }\end{array}$ \\
\hline Kontrol & Intrinsik & 9 & 0,932 & $0^{0,35}$ & & & \\
\hline
\end{tabular}

Berdasarkan tabel 8 di atas, diketahui nilai Asymp Sig (Asymp Sig 2-tailed) kelompok Eksperimen sebesar 0,017, Sedangkan nilai Asymp Sig (Asymp Sig 2-tailed) pada kelompok kontrol sebesar 0,350, yang lebih besar dari 0,05 yang artinya nilai Asymp Sig 2-tailed motivasi belajar intrinsik Kelompok Eksperimen dan Kelompok kontrol berdistribusi normal.

Tabel 9 Hasil uji Post-test / kemampuan akhir hasil belajar antara kelompok eksperimen dan kelompok kontrol

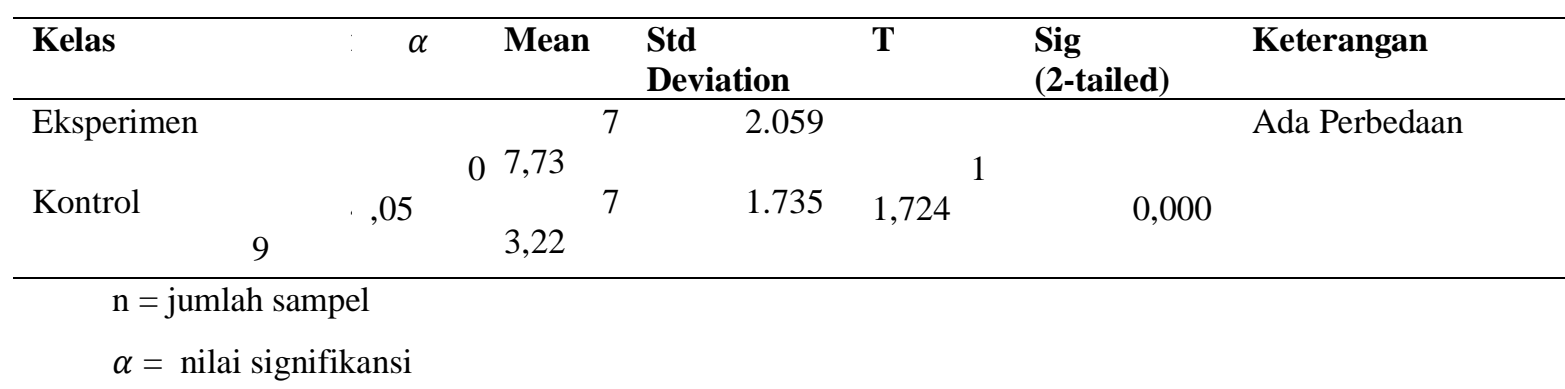

Berdasarkan tabel 9 diatas, diketahui bahwa kelas eksperimen memiliki nilai mean 77,73 dan nilai standard deviasi sebesar 2,059, dangkan kelas kontrol memiliki mean 73,22 dan nilai standard deviasi sebesar 1,735. Sedangkan nilai t dan nilai signifikansi sig (2- tailed) pada kelas eksperimen dan kelas kontrol sebesar 11,724 dan 0,000. Berdasarkan nilai signifikasnsi sig (2- tailed) pada kelas eksperimen dan kelas kontrol sebesar 0,000 yang lebih kecil dari 0,05 yang artinya ada perbedaan kemampuan ahir hasil belajar antara Kelas Eksperimen dan Kelas Kontrol, setelah kelas eksperimen diberi perlakuan dengan model pembelajaran berbasis masalah dan kelas kontrol tidak di beri perlakuan dengan model pembelajaran berbasis masalah.

Tabel 10 Hasil Uji Post-test / Kemampuan Akhir Motivasi Belajar Kelmpok Eksperimen dan Kelompok Kontrol.

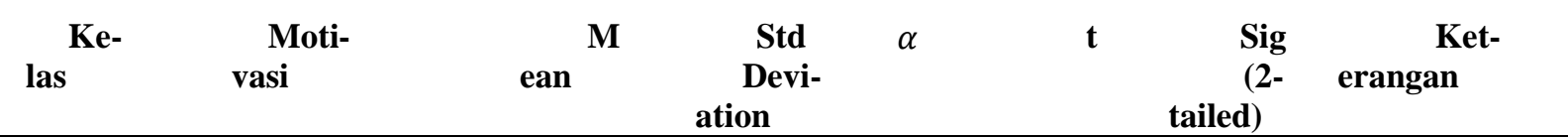




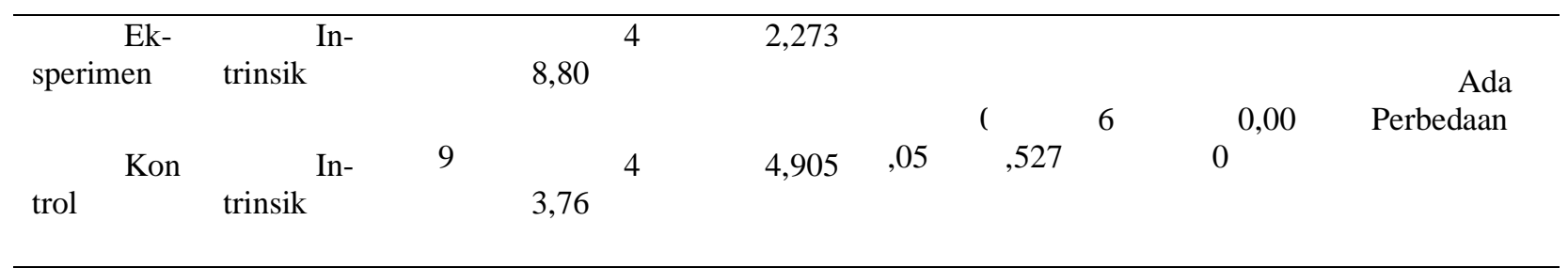

\section{n = jumlah sampel}

$\alpha=$ nilai signifikansi

Berdasarkan tabel 10 di atas, diketahui pada kelompok eksperimen nilai mean-nya 48,80 dan nilai standard deviasinya 2,273, sedangkan pada kelompok kontrol nilai mean-nya sebesar 43,76 dan nilai standard deviasinya sebesar 4,905. Sedangkan nilai t dan nilai signifikansi t ( sig 2-tailed) pada kelompok eksperimen dan kelompok kontrol sebesar 6,527 dan 0,000 yang lebih kecil dari 0,05 yang artinya terdapat perbedaan motivasi belajar intrinsik antara kelompok eksperimen setelah menggunakan Model Pembelajaran Berbasis Masalah dengan kelompok kontrol yang tidak mendapatkan perlakuan dengan model pembelajaran berbasisi masalah, atau ada pengaruh Model Pembelajaran Berbasis Masalah Terhadap Motivasi Belajar Intrinsik pada kelompok Eksperimen.

\section{SIMPULAN}

Tidak ada perbedaan motivasi belajar dan hasil belajar antara kelompok eksperimen dan kelompok kontrol sebelum mengunakan model pembelajaran berbasis masalah pada mata pelajaran Geografi di SMA Tahfidz Darul Ulum Banyuanyar Pamekasan. Ada perbedaan motivasi belajar dan hasil belajar antara kelompok eksperimen dan kelompok kontrol setelah menggunakan model pembelajaran berbasis masalah atau ada pengaruh model pembelajaran berbasis masalah terhadap motivasi dan hasil belajar pada mata pelajaran Geografi di SMA Tahfidz Darul Ulum Banyuanyar Pamekasan.

Sebelum menggunakan dan menerapkan model PBM pada KBM maka persiapkanlah terlebih dahulu RPP, media pembelajaran dan tempat belajar yang baik dan suasana kelas yang kondusif serta diusahakan bagi pendidik mengetahui kompetensi siswa sebelum memulai KBM agar kegiatan KBM dapat berjalan dengan lancar dan baik. Di usahakan bagi pendidik agar mengusai dan memahami langkah-langkah model pembelajaran berbasis masalah, mampu mengkondisikan siswa dan menarik minat serta memotivasi siswa pada awal kegiatan pembelajaran. Bagi pendidik, kepala sekolah dan pihak sekolah agar menyediakan sarana pembelajaran dan sumber belajar yang sesuai dan yang di butuhkan oleh peserta didik dan pendidik yang ingin menggunakan dan menerapkan model pembelajaran berbasis masalah di dalam kelas. Bagi kepala sekolah dan pihak sekolah agar memberikan pelatihan kepada pendidik yang tidak bisa menggunakan dan mengoperasikan computer / laptop, LCD Proyektor dan menyediakan, melengkapi sarana belajar dan media pembelajaran seperti LKS, buku paket dan LCD Proyektor bagi pendidik yang ingin menggunakan dan menerapkan model pembelajaran berbasis masalah.

\section{Referensi}

Abdul Majid, (2014) Chaerul Rochman, Pendekatan ilmiah dalam implementasi kurikulum. Bandung: PT Remaja Rosdakarya.

Abin Syamsudin Makmun (2007), Psikologi Kependidikan: Perangkat Sistem Pengajaran Modul. Bandung: PT Remaja Rosdakarya.

Amirullah, populasi dan sampel, (pemahaman, jenis dan teknik) Disarikan dari buku; Metode Penelitian Manajemen (2015) Penerbit. Bayumedia Publishing Malang),

Arina Restian (2015), Psikologi Pendidikan: Teori dan Praktek. Malang: UMM Press.

Bambang Utoyo (2009), Geografi Membuka Cakrawala Dunia untuk kelas x SMA.Jakarta:Pusat Perbukuan Departemen Pendidikan Nasional.

Bernandus Sanjaya (2015), Pengantar Membangun Teori Penelitian: Merajut Kesangsian Menggapai Kebenaran. Jakarta: Prestasi Pustakarya. 
Danang Endarto dkk (2019), Geografi untuk SMA Kelas X. Jakarta : Pusat Perbukuan, Departemen Pendidikan Nasional.

entari Darma Putri (2014), Pengaruh penerapan model pembelajaran berbasis masalah terhadap hasil belajar fisika dan sikap ilmiah siswa di smpn 11 kota bengkulu (universitas bengkulu 2014)

Habibah Sukmini dkk (2016), Meningkatkan Motivasi Belajar Melalui Pendekatan Problem-Based Learning (Pbl), Jurnal Pena Ilmiah: Vol. 1, No. 1.

Hamzah B. Uno (2012), Teori motivasi dan pengukurannya, analisis dibidang pendidikan. Jakarta: PT Bumi Aksara.

Happy Kamala Rizqi, Siti Zubaidah, Nursasi Handayani , 2015 (Pengaruh Problem Based Learning (PBL) Terhadap Motivasi dan Hasil Belajar Siswa Kelas VII SMP Brawijaya Smart School Malang, Article · January 2015)

Hartono (2009), Geografi 1 Jelajah Bumi dan Alam Semesta untuk kelas X SMA .Jakarta: Pusat Perbukuan, Departemen Pendidikan Nasional.

Herlina dkk, Pengaruh Model Problem Based Learning dan Motivasi Berprestasi Terhadap Hasil Belajar Siswa Pada Mata Pelajaran Biologi di Kelas XI IPA MAN 2 Model Palu.

Idrus Alwi, kriteria empirik dalam menentukan sampel pada pengujian hipotesis statistika dan analisis butir (Jurnal Formatif 2(2): 140-148, Program Studi Pendidikan Matematika, Universitas Indraprasta PGRI Jakarta)

Kompri (2016), Motivasi Pembelajaran Perspektif Guru dan Siswa, Bandung: PT Remaja Rosdakarya.

L. A. Kharida dkk (2009), PENERAPAN MODEL PEMBELAJARAN BERBASIS MASALAH UNTUK PENINGKATAN HASIL BELAJAR SISWA PADA POKOK BAHASAN ELASTISITAS BAHAN (Jurnal Pendidikan Fisika Indonesia 5 (2009))

Linawati (2017), Pengaruh Model Pembelajaran Bebasis Masalah (Problem Based Learning) dengan Metode Resitasi Terhadap.Peningkatan Motivasi dan Keaktifan Belajar Mahasiswa Akuntansi Universitas Nusantara PGRI Kediri, Seminar Nasional Hasil Penelitian Universitas Kanjuruhan Malang 2017

M. Ngalim Purwanto (2014), Psikologi Pendidikan. Bandung: PT Remaja Rosdakarya.

Melli Fitriani (2017) Pengaruh Model Problem Based Learning Terhadap Motivasi Belajar Sistem Koordinasi Pada Siswa Di Sma Negeri 2 Bantaeng (Jurnal Biotek Volume 5 Nomor 1 Juni 2017).

Melly Fitiani, pengaruh model problem based learning terhadap motivasi belajar sistem kordinasi pada siswa di sma negeri 2 banteng (artikel/jurnal, Universitas Indonesia Timur Kampus V UIT).

Mentari Darma Putri (2014), Pengaruh penerapan model pembelajaran berbasis masalah terhadap hasil belajar fisika dan sikap ilmiah siswa di smpn 11 kota bengkulu (universitas bengkulu 2014)

Mismiati. 2017, Pengaruh Motivasi Belajar Siswa Dan Penggunaan Media Pembelajaran Terhadap Prestasi Belajar Mata Pelajaran Ips Siswa Sdn 2 Mrican, Kecamatan Jenangan, Kabupaten Ponorogo (Jurnal Penelitian dan Pendidikan IPS (JPPI) Volume 11 No 1 (2017) 54-75)

Moh. Wahyu Kurniawan dan Wuri Wuryandani (2017) dengan judul" Pengaruh Model Pembelajaran Berbasis Masalah terhadap Motivasi Belajar dan Hasil Belajar PPKn, Mahasiswa PPS Universitas Negeri Yogyakarta PPS Universitas Negeri Yogyakarta (Jurnal Civics, Volume 14, Nomor 1, Mei 2017 10).

Muhammad Fathurrohman 2017. Model-Model Pembelajaran Inovatif. Jogjakarta: AR-RUZZ MEDIA.

Muhammad Fathurrohman dan Sulistiyorini (2018), Belajar dan Pembelajaran Meningkatkan Mutu Pembelajaran Sesuai Standar Nasional. Yogyakarta: Kalimedia.

Munawir Anas (2017), Pengaruh Model Pembelajaran Berbasis Masalah Terhadap Hasil Belajar Matematika Peserta didik Kelas IV Min Sepabatu Kecamatan Tinambung Kabupaten Poliwali Mandar (Skripsi, Universitas Alaudin Munandar, 2017),

Nana Syaodih Sukmadinata (2011), Landasan Psikologi Proses Pendidikan .Bandung: PT Remaja Rosdakarya.

Ni Nyoman Sri Lestari, pengaruh model pembelajaran berbasis masalah dan motivasi belajar terhadap prestasi belajar fisika bagi siswa kelas VII SMP, Program Studi Teknologi Pembelajaran Program Pasca Sarjana Universitas Pendidikan Ganesha Singaraja.

Nuryadi dkk (2017), Dasar-Dasar Statistik Penelitan. Yogyakarta: Sibuku Media. 
Pradnyana (2013), P.B., Marhaeni, A.A.I.N., Candiasa, I Made dengan judul “ Pengaruh Pembelajaran Berbasis Masalah Terhadap Motivasi Belajar Dan Presttasi Belajar Matematika Siswa Kelas IV SD, Program Studi Pendidikan Dasar, Program Pascasarjana Universitas Pendidikan Ganesha Singarja, Indonesa ( e-Journal Program Pascasarjana Universitas Pendidikan Ganesha Jurusan Pendidikan Dasar (Volume 3 Tahun 2013)

Purwa Atmaja Prawira (2013), Psikologi pendidikan dalam perperktif baru. Jogjakarta: Ar Ruzz Media.

R. Ananda dkk (2018), Statistika Pendidikan, Teori dan Praktek Dalam Pendidikan .Medan: CV Widya Puspita.

Ramlawati (2017), Pengaruh Model PBL (Problem Based Learning) terhadap Motivasi dan Hasil Belajar IPA Peserta Didik (Jurnal Sainsmat, Maret 2017)

Ramlawati dkk (2017), Pengaruh Model PBL (Problem Based Learning) terhadap Motivasi dan Hasil Belajar IPA Peserta Didik J (urnal Sainsmat, Maret 2017).

Riana Rahmasari (2016), penerapan model pembelajaran Problem Based Learning untuk meningkatkan hasil belajar ipa pada siswa kelas IV SD Negeri Ngelompong Sleman Yogyakarta (Yogyakarta, UNY, Agustus 2016)

Riduan (2014), Metode dan teknik menyusun tesis. Bandung: Alfabeta.

Rochmat Aldy Purnomo (2016), Analisis Statistik Ekonomi dan Bisnis dengan SPSS CV(Ponorogo: Wade Group.

Rusman (2014), PENERAPAN PEMBELAJARAN BERBASIS MASALAH (Edutech, Tahun 13, Vol.1, No.2, Juni 2014)

S. Budiwanto (2017), Metode Statistika Untuk Mengolah Data Keolahragaan, Fakultas Ilmu Keolahragaan Universitas Negeri Malang. UM.

Sardiman (2017), Interaksi dan motivasi belajar mengajar. Jakarta : PT Raja Grafindo Persada.

Sugiono (2014), Metode Penelitian Kuantitatif Kualitatif dan R\&D .Bandung: Alfabeta.

Suharsimi Arikunto (2014), Prosedur penelitian suatu pendekatan praktek. Jakarta: Rineka Cipta.

Syofian Siregar (2017), Metode Penelitian Kuantitatif, dilengkapi dengan perhtungan manual dan SPSS. Jakarta: kencana.

Usman Rianse (2012), Metodologi penelitian social ekonomi. Bandung: Alfabeta.

V.W. Sujarweni (2015), SPSS untuk penelitian. Yogyakarta: Pustaka Baru Press.

Wahid Murni (2008), cara mudah menulis proposal dan laporan penelitian lapangan .Malang: UM Press.

Windi Cindiana Karim (2014) Pengaruh Penggunaan Media Pembelajaran Terhadap Motivasi Belajar Siswa Pada Mata Pelajaran Pendidikan Kewarganegaraan Di Sma Negeri 1 Telaga (Jurnal Pendidikan Kewarganegaraan, UNG - 2014). 